\title{
Shared Book Reading and Word Learning in Preschool Children
}

\author{
Fernanda Pires Garcia \\ Aline Melina Vaz \\ Andréia Schmidt ${ }^{1}$ \\ Faculty of Philosophy, Sciences and Letters at Ribeirão Preto, University of São Paulo, \\ Ribeirão Preto, SP, Brazil
}

\begin{abstract}
Shared story reading is an effective way to promote the learning of vocabulary for children, however, the basic processes involved in this learning have yet to be clarified. The aim of this study was to investigate the influence of social cues on word learning while reading books, and whether the new word-picture relationships presented in the stories sustain subsequent performance by exclusion, given unknown pictures. Two non-commercial illustrated stories, containing two pseudowords each, were read with and without the presentation of social cues for 12 children, 3 years of age, in a repeated measures design. Matching, exclusion and naming probes evaluated the learning of these pseudowords. The performance of the children did not differ in relation to the learning of the pseudowords in both reading conditions (with presentation of social cues and without cues), and all presented performance by exclusion in the planned probes. These results confirm that the shared reading situation promotes the learning of new relationships between words and pictures, however, do not verify the role of social cues in this process.
\end{abstract}

Keywords: Shared book reading, learning words, verbal behavior, behavior analysis.

\section{Leitura Compartilhada de Livros e Aprendizagem de Palavras em Crianças Pré-Escolares}

\section{Resumo}

A leitura compartilhada de histórias é uma forma eficiente de promover a aprendizagem de vocabulário por crianças, mas os processos básicos envolvidos nessa aprendizagem ainda precisam ser esclarecidos. O objetivo deste estudo foi investigar a influência de dicas sociais na aprendizagem de palavras durante a leitura de livros, e se as novas relações palavras-figuras apresentadas nas histórias sustentariam um desempenho por exclusão posterior, diante de figuras desconhecidas. Duas histórias ilustradas não comerciais, contendo duas pseudopalavras cada, foram lidas com e sem a apresentação de dicas sociais para 12 crianças de 3 anos, em um delineamento de medidas repetidas. Sondas de emparelhamento, exclusão e nomeação avaliaram a aprendizagem dessas pseudopalavras. $\mathrm{O}$ desempenho das crianças não diferiu

Mailing address: University of São Paulo, Faculty of Philosophy, Sciences and Letters at Ribeirão Preto, Department of Psychology, Av. Bandeirantes, 3900, Bairro Monte Alegre, Ribeirão Preto, SP, Brazil 14040901. E-mail: aschmidt@ffclrp.usp.br

The third author is member of the National Institute of Science and Technology on Behavior, Cognition, and Teaching (INCT-ECCE), supported by the National Research Council (CNPq, grant \#573972/2008-7) and the State of São Paulo Foundation for Research Support (FAPESP, grant \# 08/57705-8). This research was also supported by FAPESP, grant \# 2014/22990-5, awarded to Andréia Schmidt. 
em relação à aprendizagem das pseudopalavras nas duas condições de leitura (com apresentação de dica social e sem dicas), e todas apresentaram desempenho por exclusão nas sondas planejadas. Esses resultados confirmam que a situação de leitura compartilhada promove aprendizagem de novas relações entre palavras e figuras, mas deixam em aberto o papel de dicas sociais nesse processo.

Palavras-chave: Leitura compartilhada de livros, aprendizagem de palavras, comportamento verbal, análise do comportamento.

\section{Lectura Compartida de Libros y Aprendizaje de Palavras en Niños en Edad Preescolar}

\section{Resumen}

La lectura compartida de libros es una manera eficaz de promover el aprendizaje de vocabulario de los niños, pero los procesos básicos que intervienen en este aprendizaje todavía necesitan ser aclarado. El objetivo de este estudio fue investigar la influencia de pistas sociales en el aprendizaje de palabras durante la lectura de libros, y se nuevas relaciones nombre-figuras presentado en las historias, mantienen subsecuenteresponder por exclusión, delantenuevas figuras desconocidas. Dos historias ilustradas no comerciales, que contienen dos pseudopalabras cada uno, fueron leídas con y sin la presentación de pistas sociales a 12 niños de 3 años. Pruebas de aprendizaje, exclusión y respuesta verbal evaluaron el aprendizaje de estos pseudopalabras. El desempeño de los niños no difirió en relación al aprendizaje de la pseudopalabra, bajo dos condiciones de la lectura, pero todos mostraron respuesta de exclusión en las pruebas previstas. Estos resultados confirman que la situación lectura compartida promueve el aprendizaje de vocabulario, pero dejan abierta la función de laspistas sociales en este proceso.

Palabras clave: Lectura compartida de libros, aprendizaje de palabras, comportamiento verbal, análisis de la conducta.

Verbal behavior, according to Skinner (1957), is defined as any behavior reinforced by the mediation of the listener, who was specifically taught to behave as a mediator. Considering the eminently social nature of verbal behavior, Skinner advocates a functional approach in its study. For this author, verbal behavior is learned in the interaction of the person with his/her social environment, with this process of interaction involving variables related to the conditions in which a particular verbal response is issued, the characteristics of the response and the consequences produced by this response (analysis of verbal contingencies). Accordingly, the cultural practices of a given community are crucial for its members to be able to learn repertoires of speakers and listeners, with these practices being conducted in the form of direct teaching, as when parents (or adults in general) are actively engaged in establishing appropriate contingencies for learning the verbal repertoire, or indirectly, when the child is included in common activities of its group and exposed to situations that favor the development of this repertoire.

In Western culture, reading books (illustrated or not) for children (shared reading) is a fairly common practice. It is referred to by many authors as one of the most important activities for learning and expansion of vocabulary in children (Elley, 1989; Mol, Bus, de Jong, \& Smeets, 2008), as well as providing the opportunity for them to learn the meaning of new words (Farrant $\&$ Zubrick, 2013). From a behavioral perspective, the expansion of the child's vocabulary from the shared story reading may occur due to a series of contingencies present in the situation and that promote such learning. In some of these, reading promotes the opportunity for the child to directly relate words and pictures present in illustrated books, with or without direct instruction from the adult, so that the child is able to select the 
picture that corresponds to the new word or use the word in its proper context (to name an object or request it from an adult). This occurs, for example, when the adult points to, or calls the child's attention to a particular picture during the reading (auditory-visual pairing - Stemmer, 1996; Vichi, Nascimento, \& Souza, 2012), or by simply reading the story while the child inspects the illustrations of the book, relating, without any direct instruction, the unknown words in the story to elements of the illustration that were also unknown (performance by exclusion - Dixon, 1977).

On other occasions, the reading may encourage the child to relate certain unknown words to less obvious aspects of the illustrations because of lexical cues present in the sentences of the story (Mintz \& Gleitman, 2002), in a more refined stimulus control process. For example, when a child hears the phrase "The apple was in the magenta basket", the position of the word "magenta" in the phrase indicates that it is related to the word "basket", being a property of this; thus, the child may be under the control of a specific property of the "basket" - its color, which, in this case, would promote the learning of an adjective. Older children with greater experience with the language syntax, would be able not only to learn the meaning of new words that appear in the stories, but also the occasion in which they are used, and their relationship with other words of the language, merely through verbal cues present in the course of the story. These are just some of the stimulus control processes that may be present in the shared reading situation, however, they have been little explored by behavior analysts, despite the vast literature on the subject produced by other theoretical traditions (e.g., Biemiller \& Boote, 2006; Kucirkova, Messer, \& Sheehy, 2014; Wilkinson \& HoustonPrice, 2013).

Specifically, two processes have been suggested by different authors of the cognitive tradition as being implicated in vocabulary learning by children in shared reading situations: fast mapping and social-pragmatic cues. Fast mapping is referred to by Horst (2013) as a key process in learning words in shared reading situ- ations, especially in illustrated books: children tend to relate the unknown words in the story to the also unknown elements of the illustrations, establishing a partial understanding of the "meaning" of the word.

In Behavioral Analysis, the process of relating undefined stimuli, in contrast to known stimuli, is known as "responding by exclusion" (Dixon, 1977). When hearing a story, the child can come into contact with a word unknown (e.g., "hippopotamus") and, when looking at the illustration of the page, sees the picture of an elephant, a lion (both known) and a hippopotamus (unknown). Without any direct instruction, the child tends to relate the unknown word to the unfamiliar picture, excluding other known pictures of the illustration from being potentially "related" to the new word.

This emergent (untaught) performance is defined as the immediate selection of an undefined comparison stimulus (unknown picture or object, which has no relation to any specific stimulus of the environment) when presented with a also undefined sample stimulus (for example, an unknown spoken word), without a prior history that makes the comparison stimulus discriminative for the selection response (Oshiro, de Souza, $\&$ Costa, 2006). This process has been identified by many authors as underlying vocabulary learning in different situations (e.g., Carey \& Bartlett, 1978; Halberda, 2006; Heibeck \& Markman, 1987; McIlvane \& Stoddard, 1981; Wilkinson, Dube, \& McIlvane, 1998). Evidence of the occurrence of responding by exclusion in situations of shared book reading was found by Horst, Parsons and Bryan (2011) in a study conducted with children, 3 years of age, which showed that children are able to relate new words to unknown elements in the illustrations of a book without the direct teaching of these relationships. The other process cited as potentially important as an aid in learning new words in the situation of shared story reading is called social-pragmatic cues.

According to Farrant and Zubrick (2013), book reading by the adult in the natural environment involves a structured situation in which the social cues provided (gestures of pointing to the pictures of the stories, the naming of specific 
aspects of the illustration and the establishment of joint attention, for example) provide an opportunity for children to learn to map referents corresponding to unknown words present in the story. Examples of social cues may be facial expression, gestures, gaze direction, pointing, and giving emphasis, among other possibilities.

Various studies on vocabulary acquisition evidence the importance of social cues for the learning of relations between words and their referents. A longitudinal study by Thoermer and Sodian (2001) with children between 10 and 12 months of age, for example, has shown that babies accompanied the communicative gestures of adults, although initially without comprehending the intentional relationship between the gesture and the referent, regardless of the communicative situation. A study by Rowe (2000) indicated that mothers who talk frequently with their babies also present a high frequency of the pointing gesture. Booth, McGregor and Rohlfing (2008), in a study of 80 children aged 2831 months, found that the overlapping of social cues (looking at and pointing, for example, or looking at and manipulating objects) in the situation of naming objects unknown to the children produces more positive effects regarding the attention and performance of the children in learning tasks, than isolated social cues.

Furthermore, there is empirical evidence that babies who present joint attention, directing their attention to the same focus (action or object) as the direction of adult gaze, during an episode of verbal interaction, better establish the relationship between words and their referents (Carpenter, Nagell, \& Tomasello, 1998; Yu \& Smith, 2012). A study by Yu and Ballard (2007), in which videos of interactions between mothers and their babies were analyzed, shows that babies learn the meaning of words depending on the frequency of their occurrence when presented with their referents, as well as depending on the social cues provided by the adults. In this study, the authors found that mothers tend to synchronize their naming with the direction of their gaze and gestures (such as pointing toward the named objects), while the babies are looking at these objects or manipulating them. All these data suggest that gestural cues have a facilitating effect on the learning of words.

However, no studies were found that specifically investigated the effect of the cue of pointing to book illustrations on the learning of new words in the shared reading situation. Generally, the cues investigated more frequently in studies on shared reading are the verbal cues: asking questions of different types (Blewitt, Rump, Shealy, \& Cook, 2009), explain the meaning of new words (Biemiller \& Boote, 2006), specifically naming the undefined elements of the story (Justice, 2002), commenting on the new words (Ard \& Beverly, 2004), giving prompts and feedback for the comments of the participant (Flores, Pires, \& Souza, 2014) or presenting new words in multiple contexts (Wilkinson \& Houston-Price, 2013). Verbal cues, however, seem to be most useful for more experienced speakers capable of being under the control of semantic and lexical aspects of the phrases. Younger children, however, seem to strongly benefit from the illustrations in children's books (Evans \& Saint-Aubin, 2013; Ganea, Allen, Butler, Carey, $\&$ DeLoache, 2009) and gestural cues that target this component of the stories can be relevant in the learning of these children.

In addition, the learning measures used in studies on learning from shared story reading are variable, involving the measurement of the number of learned words after the reading situation (measured by picture selection tests from a dictated word sample - e.g., "Show me where the 'blicket' is") or general measures of vocabulary, measured by tests such as the Peabody Pictures Vocabulary Test - PPVT (Dunn \& Dunn, 1997), or tests that assess whether the child is able to describe the meaning of certain words. It must be considered, however, that word learning is a process that involves different repertoires, that range from the discrimination that the particular word has already been heard (or the object/ picture/property to which the word refers is not completely unknown) to being able to use the learned word in its proper context (e.g., naming or the use of the word in a request situation). The 
importance of evaluating the learning of words that the child was effectively exposed to in the reading situation, however, in different contexts, must also be considered. It does not seem logical to expect the shared reading situation to produce a general increase in the vocabulary of the child, however, it is reasonable to expect that learning certain words present in the story read can be reflected in different repertoires of the child.

Maintaining control over other variables, such as the illustrations of the book and the number of repetitions of the unknown words, the aim was to investigate the effect that a specific social cue - the gesture of pointing to illustrations of a book - can have on learning new words through story reading. The aim of this study was to verify whether children, three years of age, can more easily learn name-picture relationships from the reading of illustrated stories, read to them with the presentation of social cues provided by an adult, compared to reading without these cues. The measures of learning used were specific in relation to the words that the children were effectively exposed to during the reading: the recognition (or not) of a previous contact with the undefined word (exclusion probe), the selection of the object corresponding to the dictated pseudoword (matching-to-sample probe) and the naming of the unknown picture that appeared in the story (naming probe).

\section{Method}

\section{Participants}

The study included 12 children, 3 years of age, without indications of developmental delay, according to the report of the teachers, who attended a day care center of a city in the state of Sao Paulo. The parents were informed about the study and authorized the participation of the children through signing an informed consent form.

\section{Materials}

Six pseudowords (three syllables) were invented for this study: fulito, patuce, vicopa, xineque, niveco and pafile. In addition, six ob- jects of undefined shapes were made from scrap items and colored paper. In this study, these objects were named as "undefined object" (due to not previously being relate to any words of the language), and were randomly assigned as the referents of the pseudowords. Four of these pseudowords and their respective undefined referent objects appeared, in pairs, in two storybooks. The other two undefined objects and pseudowords were used in the Exclusion Probes.

The two children's storybooks (Book 1 and Book 2), both with 11 pages, were constructed with content appropriate for the age of the children (describing everyday situations such as):

It was a beautiful day, it was hot, everyone was happy and they had all day to enjoy themselves. Amanda was afraid of spoiling her fulito, she decided to put it away so she could play on the swing without fear of breaking her toy.

The pages of both books were composed of illustrative photos and a short piece of text (three to six lines, Arial font, 28 point), which was presented just below the picture, following the format of several commercial children's books (see Figure 1). In each book, a pair of pseudowords was presented. The pseudowords "Fulito" and "Xineque" appeared in Book 1, with "Vicopa" and "Patuci" in Book 2. Each pseudoword was presented three times throughout the story, accompanied by an illustration of its respective undefined object. The images of the two undefined objects did not appear simultaneously in any of the illustrations of the books.

For the verification of the learning of the pseudowords a Test Book for each storybook was also made, containing 16 pages. A set of four pictures was presented on each of the first eight pages of the book (one in each quadrant) and, in each, the researcher asked the child to point to one of the pictures according to the name spoken (e.g., "Where is the car?" or "Point to where the Patuci is"). On the last eight pages of the book, a single picture was presented per page. Accordingly, the tasks of the children were described on each page.

The first four pages of the Test Book contained only pictures of known objects (e.g., dog, 


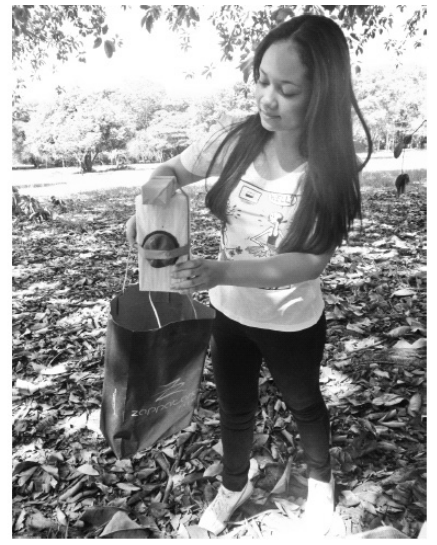

Amanda estava com medo de estraga seu fulito, então resolveu guardá-lo para poder brincar no balanço sem medo de quebrar seu brinquedo.

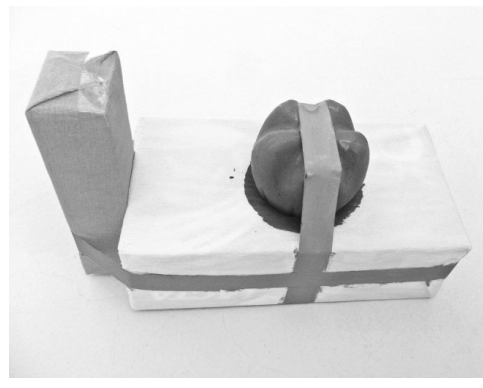

FULITO

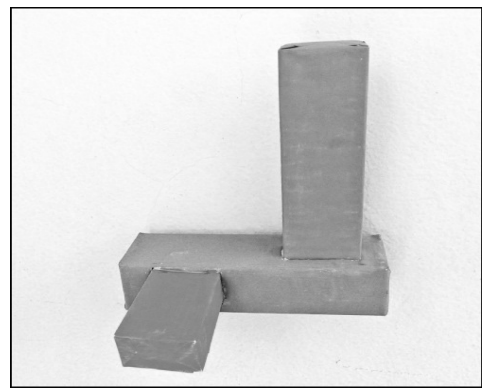

VICOPA

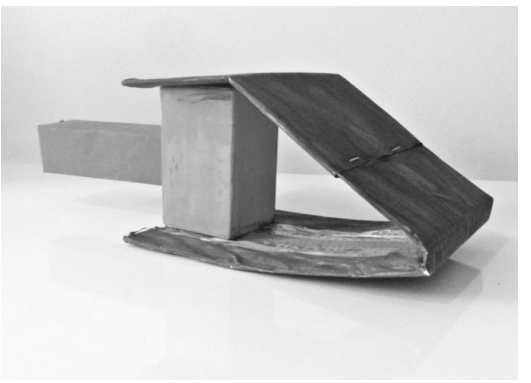

XINEQUE

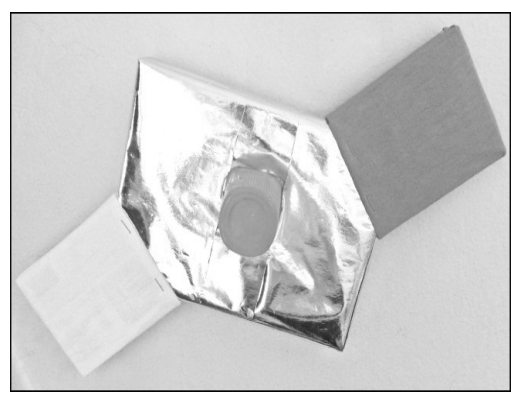

PATUCI

Figure 1. Example of a page from Book 1 (left) and figures of the undefined objects that appeared in Books 1 and 2 (right). Text of Book 1: Amanda was afraid of spoiling her fulito. She decided to put it away so she could play on the swing without fear of breaking her toy.

toy car), in order for the child to comprehend the auditory-visual discrimination task (select a picture when given a name dictated by the researcher). The two pictures of undefined objects in the book and two known pictures of toys were presented on the following two pages. On these pages matching-to-sample probes were applied, in which the child should select the picture corresponding to the pseudoword given (one trial for each word). The next two pages were used for the application of the two Exclusion Probes. The pictures of the undefined objects present in the story, the picture of a completely new undefined object and a picture of a known toy were presented on these two pages.

Finally, on the last eight pages of the test book the two pictures of the two undefined objects present in the story were presented individually, among six pictures of objects known to the children. For each picture, the researcher asked what the name of the object shown in the picture was (Naming Probes).

\section{Procedures}

After an introduction by the researcher with the participating children in their classes, each child was individually invited to go into a room to hear a story. The reading could be conducted in two different conditions.

In the "No Cue" (NC) Condition, the researcher read the book sequentially, without interruptions and without making any gesture towards the pictures. When the first reading was finished, the researcher looked at the child and said, "I'm going to read it again", and began the second reading. The same happened for a third reading of the book. In the "With Cue" (WC) Condition three readings of the book were also performed and during each reading (but without interrupting it), the researcher put her finger on (pointed at) the picture corresponding to the pseudoword, when it was read in the story ("social cue"). Care was taken that no pauses or emphasized on the pseudowords were made when presenting the cues. As each of the two unde- 
fined pictures appeared three times in the story, in each of the readings the cue was provided on a different page of the book. In total, in the WC Condition the researcher pointed three times to each of the undefined pictures (one cue for each pseudoword, for each reading). All the participants received the same cues.

All the children passed through the two reading conditions, with a period of one week between conditions (repeated measures design Cozby, 2003). For half the children, the NC condition was conducted with Book 1 and WC condition with Book 2. For the other half, this was done in reverse. The order of presentation of the conditions was also counterbalanced in relation to the participants. In both conditions, shortly after the three readings of the book, matching, exclusion and naming probes were conducted. In the Matching Probes the child was asked to point to one of the four pictures present on the page after their names were given by the researcher (e.g., "Where is the ball?", or "Where is the Xineque?"). In the Exclusion Probes two completely new pseudowords, which did not appear in the stories, were given and the child needed to point to the picture of a completely new undefined object present only in the Test Book. In the Naming Probes the child needed to answer with the name of the picture presented ("What is the name of this picture?"), for the pictures of defined objects as well as for those of the undefined objects.

The set of probes therefore verified whether: (a) the child had learned the pseudowordundefined picture relation from the presentation of these relations during the reading of the story; (b) the child was able to discriminate pictures of undefined objects present in the story (and their respective names) from undefined pictures and completely new pseudowords in exclusion probes, selecting the new undefined picture when presented with a new pseudoword; (c) the child was be able to name the undefined pictures presented in the storybook.

The performance of the children in the presentation of the probes was filmed. During the probes, the researcher took notes of the response given by the child on a record sheet and the notes were compared to the filming. For data analysis, correct and incorrect responses of the participants in the matching, exclusion and naming probes were calculated, in both conditions. The learning of the pseudowords, assessed by absolute frequency of correct responses in the matching probes, was compared in the $\mathrm{WC}$ and NC conditions using the Wilcoxon nonparametric test. The percentages of correct responses of the pseudowords, in their respective conditions, were compared using the Friedman nonparametric test, followed by pairwise multiple comparisons using the Nemenyi test. The significance level was .05 , with the analysis carried out using the XLStat program, 2014 version.

This study was approved by the Research Ethics Committee of the Faculty of Philosophy, Sciences and Letters at Ribeirão Preto University of São Paulo - USP (Certificado de Apresentação para Apreciação Ética [CAAE] 15832813. 0.0000.5407).

\section{Results}

All the participants demonstrated comprehension of auditory-visual discrimination task, correctly selecting the pictures of known objects when presented with their names in the first four trials with the test book. In both conditions, comparing the performance only in the Selection Probes, the occurrence of partial learning of the name-picture relationships was observed, as shown in Table 1.

In the $\mathrm{NC}$ condition, considering the data of the group, 14 correct responses were calculated out of 24 possibilities; six participants presented correct responses in both probes, however, four did not present learning of either of the two words. The mean learning was 1.17 words. In the WC condition 15 correct responses were calculated and, again, six participants correctly responded in all the probes; three children, however, showed no learning of either of the two words. In this condition, the mean number of correct responses of the participants was 1.25 words. When the pairwise comparison was performed, there was no significant statistical difference between the two conditions $(W=3.0 ; p$ 
Table 1

Correct $(\sqrt{ })$ and Incorrect (-) Responses of Participants in the Matching Probes, by Pseudoword, in the Two Reading Conditions (WC - With Cue, NC - No Cue). Each Pseudoword was Tested Once

\begin{tabular}{ccccc}
\hline \multirow{2}{*}{ Participant } & \multicolumn{2}{c}{ WC Condition } & \multicolumn{2}{c}{ NC Condition } \\
\cline { 2 - 5 } & Word 1 & Word 2 & Word 1 & Word 2 \\
\hline P1 & - & - & - & - \\
P2 & - & $\sqrt{ }$ & - & $\sqrt{ }$ \\
P3 & $\sqrt{ }$ & $\sqrt{ }$ & - & - \\
P4 & $\sqrt{ }$ & $\sqrt{ }$ & $\sqrt{ }$ \\
P5 & $\sqrt{ }$ & - & $\sqrt{ }$ & - \\
P6 & - & - & $\sqrt{ }$ & $\sqrt{ }$ \\
P7 & $\sqrt{ }$ & $\sqrt{ }$ & $\sqrt{ }$ \\
P8 & - & - & $\sqrt{ }$ & $\sqrt{ }$ \\
P9 & $\sqrt{ }$ & $\sqrt{ }$ & $\sqrt{ }$ & - \\
P10 & $\sqrt{ }$ & $\sqrt{ }$ & - & - \\
P11 & $\sqrt{ }$ & - & - & \\
P12 & $\sqrt{ }$ & $\sqrt{ }$ & & $\sqrt{ }$ \\
\hline
\end{tabular}

$=.68)$. Four children showed learning of the two words in the two books, and only one child did not demonstrate learning of any of the words. Overall, the results achieved in the matching probes suggest there was no difference between the two conditions proposed in this study. In the pairwise evaluation of the correct responses of the four words in the two conditions under analysis, the occurrence of the same learning pattern was observed $(\mathrm{Q}=.36, p>.05)$, indicating that none of the four pseudowords presented in the stories had specific characteristics that could specifically facilitate or hinder their learning.

The Exclusion Probes had the objective of verifying whether the children would be able to discriminate the pseudowords presented the story from other pseudowords, and whether the social cue favored this discrimination. The results indicate that all the children were able to perform this discrimination, regardless of the reading condition: the pointing cue did not have an influence on this measure. In the WC Condition, 11 of the 12 participants correctly responded to the two exclusion probes (only P10 selected the stimulus related to the word "Xineque" in the story); in the NC condition, all 12 participants responded by exclusion.

Only three participants presented the naming response for the undefined pictures. In the WC Condition, P4 (a participant who showed learning of the two words in the selection probes) managed to name both undefined figures, and P11 managed to name one of the undefined figures correctly. In the NC Condition, only P2 could correctly name one of the undefined figures.

\section{Discussion}

This study aimed to investigate whether children, 3 years of age, find it easier to learn name-picture relationships from illustrated stories read in a directed way (with social cues), compared with the reading of stories without the presence of these cues. In this study, half of the participants demonstrated learning of the two words present in the story read, regardless of the experimental condition (with or without the cue of pointing to the pictures), which indicates that the independent manipulated variable, the social 
cue, neither encouraged or hindered the learning of the new word-picture relationships. In addition, all the children, regardless of the reading condition, responded by exclusion in the probes designed for this purpose, indicating that reading stories that contain unknown words and pictures produces, at least, an initial level of learning: in the case reported here, all the children were able to discriminate the pseudowords and pictures of undefined objects present in the story from other pseudowords of pictures of entirely new undefined objects.

In general, the results obtained indicate that: (a) children in the 3 years age group can learn completely unknown words from a small number of exposures to reading from an illustrated book; (b) despite data from the literature on the role of gestural cues on the learning of vocabulary, no evidence was found of a facilitator role for the cue of pointing on this learning in the situation investigated; (c) what is usually called "vocabulary learning" from the shared book reading situation appears to be a number of different repertoires, ranging from the simplest (to discriminate the unknown word-picture relation in the book from the others) to the most complex, such as naming the pictures of undefined objects. These points are discussed in sequence.

The first point to highlight is that the preparation of the material used in the study sought to isolate the effect of the reading from the previous experiences of the children. Some studies on the effect of shared reading on learning new words use words from the language of the participants, or books that have been published (Robbins \& Ehri, 1994; Wilkinson \& HoustonPrice, 2013; Zucker, Cabell, Justice, Pentimonti, \& Kaderavek, 2013). This type of material has the advantages of not requiring the creation of specific plots for the research situation and coming with visuals resources attractive to the children, which can facilitate their engagement, as well as allowing a closer approach to the study of a natural situation. Conversely, the use of commercial books in basic studies, in which the goal is to understand the processes involved in learning vocabulary, has the disadvantage of not securely controlling the prior contact (or additional contact, during the study) of the participants with the words taught. In the present study, as well as in that of Horst et al. (2011), the books, pseudowords and pictures used were created by the researchers, which ensured that the eventual learning of the words was due to the reading procedure conducted, and not previous contact of the children with the words used or the pictures presented.

The dataset presented here is consistent with data from other studies that used book reading as a way of teaching words to preschool and schoolage children (e.g., Flores et al., 2014; Horst et al., 2011; Robbins \& Ehri, 1994; Wilkinson \& Houston-Price, 2013). Considering that four children showed learning of all the new words presented in the two books in the matching probes, and that another four children showed this performance in relation to all the words in at least one book (although the independent variable - pointing - did not prove critical in the present study), there seems to be strong evidence that the activity of reading to very young children is a propitious situation for learning new vocabulary, given certain conditions.

There is still no clarity on what the necessary and sufficient conditions are for learning through reading stories to occur, however, as stated by Horst (2013), certainly the same processes involved in learning new words in natural conditions of interaction between the child and its social context are implicated in vocabulary learning in the situation of reading illustrated stories. When an unknown word is presented in a reading situation (the same way as when it is presented in a verbal interaction situation with an adult or a couple), the child must be under control of the sequence of sounds that compose the new word, as well as under the control of cues that establish the aspect of the world to which the word refers. Repeated presentations of the same word in different contexts, either through direct linkage with its referent (when the word is displayed in the presence of only one picture) or known elements contrasting with the unknown picture that the word refers to, or simply from verbal cues (e.g., position of the words in the sentence, specific lexical cues), promote 
the repeated contact of the child with the new relationships, expanding the possibilities of the establishment of the "meaning" of the word.

In the specific case of reading books for preschool children, the illustrations play a very important role in establishing these stimulus control relations. Various studies indicate that young children spend more time looking at the illustrations of a book than at the text (e.g., Evans \& Saint-Aubin, 2005; Justice, Skibbe, Canning, \& Lankford, 2005). In addition, Evans and Saint-Aubin (2013), in a study on eye movement, showed that children synchronize the direction of their gaze on illustration with the words that are read in the story, inspecting the unknown elements for longer than the known ones. In this particular case, performance by exclusion seems important.

Given appropriate conditions, such as, for example, a large amount of known words in the story and a small proportion of unknown words (Brown, Waring, \& Donkaewbua, 2008), and illustrations presenting the unknown elements (Evans \& Saint-Aubin, 2013), the necessary contrast is established between the "known" stimuli (familiar words spoken by the reader and the pictures of the illustrations) and the unknown stimuli (unfamiliar words that occur in the story and unknown aspects of the illustrations). Without this contrast, that is, without a baseline established between most of the words present in the story and the elements of the illustrations, it is difficult for the child to manage to identify, by exclusion, the unknown stimuli of the story (Wilkinson, de Souza, \& McIlvane, 2000). In this study the evidence that the children did this throughout the repeated readings is that, in the matching-to-sample probe, at least half the children related the unknown words to the pictures of unknown objects.

In this study, it was expected that the cue of pointing by the adult would provide better conditions for the relationship between the pseudowords and undefined objects present in the illustrations to be established, thus improving the control exercised by the picture on the attention of the child. However, despite the important role played by the context of the illustrations on the learning, it was not possible to clarify the contributions of the presence or absence of the pointing cue for this kind of task. Several studies have sought to understand how gestural cues, such as pointing and looking, support the early learning of words in different situations (e.g., Thoermer \& Sodian, 2001; Tomasello, Carpenter, \& Liszkowski, 2007). There are data indicating that, in situations of verbal interaction between adults and children, adult gestural cues are important for the learning of new words by children (Booth et al., 2008). The present study, however, did not identify any significant difference in learning the pseudo-word-picture relations when participants were submitted to the WC condition, compared to the $\mathrm{NC}$ condition. It can be assumed that the number of undefined words presented together in the story (two) and the number of exposures to each of them (nine) were insufficient for the presence of the cue to have actually had any facilitating effect on the learning. Future studies could investigate whether an increased number of unknown words in the story or variations in the gestural cues presented to the child while reading exert a differential effect on the learning studied.

Finally, it must be emphasized that the set of probes performed in this study indicates that the learning of new words in all situations (including during shared story reading) involves various functionally distinct repertoires (Greer \& Du, 2015; Horst, 2013; Skinner, 1957) of different natures, which together make up what is usually called expressive and receptive vocabulary. A comprehensive analysis of these different repertoires could be useful to understand how this learning is constructed throughout the contact of the child with its verbal community and to indicate pathways regarding the variables critical for each of the different learning situations.

All the children that participated in this study presented some type of learning. P4, for example, was able to discriminate one completely new word from the unknown words heard during the story (exclusion probe), relate all the pseudowords to their corresponding pictures correctly in the matching probes and name two of the pictures; P11, in turn, managed to name a 
single unknown picture, to relate the same picture to its name in the matching probe, however, presented no similar performance regarding the other name-picture relations; while P1 did not correctly related either pseudowords to their pictures in the four matching probes or name the pictures, in the exclusion probe, this participant was able to recognize that the completely new name could not relate to the pictures already presented in the book, thus, responded by exclusion. Thus, it is noted that the learning of new words can be viewed as a continuum of interrelate repertoires that are dependent on one another. To investigate how the repeated exposure of the children to natural situations promotes the experience necessary to develop these repertoires should be a goal for all scholars of language development.

The present study presents limitations that should be considered when analyzing the results: the small number of participants, the absence of a more systematic evaluation of the development of the children and the small number of probes presented in relation to all the words investigated are the most important. Future studies should increase the number of children investigated, as well as the age groups studied, in order to verify whether the language experience or vocabulary size of the children influence the speed of learning, a question that derives from the variability of the results found in this study. In addition, it should be considered that there may have been slight variations in the way the researcher read the stories to the children, which would create uncontrolled effects, obscuring the effect of the cues presented. It is therefore suggested that future studies re-investigate the effect of social cues on the shared reading situation, as well as other contextual variables, such as the effect of the presentation of the function of an unknown object, defined in the scenario of the story, the influence of the presence of other individuals during the reading; the role of the amount of unknown words present in the same story; and the consequences of presenting other types of social cues, in isolation and simultaneously, planning more complex experimental and reading conditions in the investigations.

\section{References}

Ard, L. M., \& Beverly, B. L. (2004). Preschool word learning during joint book reading: Effect of adult questions and comments. Communication Disorders Quarterly, 26(1), 17-28. doi:10.1177/ 15257401040260010101

Biemiller, A., \& Boote, C. (2006). An effective method for building meaning vocabulary in primary grades. Journal of Educational Psychology, 98(1), 44-62. doi:10.1037/00220663.98.1.44

Blewitt, P., Rump, K. M., Shealy, S. E., \& Cook, S. A. (2009). Shared book reading: When and how questions affect young children's word learning. Journal of Educational Psychology, 101(2), 294-304. doi:10.1037/a0013844

Booth, A. E., McGregor, K. K., \& Rohlfing, K. J. (2008). Socio-pragmatics and attention: Contributions to gesturally guided word learning in toddlers. Language Learning and Development, 4(3), 179-202. doi:10.1080/15475440802143091

Brown, R., Waring, R., \& Donkaewbua, S. (2008). Incidental vocabulary acquisition from reading, reading-while-listening, and listening. Reading in a Foreign Language, 20, 136-163.

Carey, S., \& Bartllet, E. (1978). Acquiring a single new word. Papers and Reports on Child Language Development, 15, 19-29.

Carpenter, M., Nagell, K., \& Tomasello, M. (1998). Social cognition, joint attention, and communicative competence from 9 to 15 months of age. Monographs for the Society of Research in Child Development, 63(4), 1-143. doi:10.2307/1166214

Cozby, P. (2003). Métodos de pesquisa em ciências do comportamento. São Paulo, SP: Atlas.

Dixon, L. S. (1977). The nature of control by spoken words over visual stimulus selection. Journal of the Experimental Analysis of Behavior, 27, 433442. doi:10.1901/jeab.1977.27-433

Dunn, L. M., \& Dunn, L. M. (1997). Peabody picture vocabulary test - Revised. Circle Pines, MN: American Guidance Service.

Elley, W. B. (1989). Vocabulary acquisition from listening to stories. Reading Research Quarterly, 24(2), 174-187. doi:10.2307/747863

Evans, M. A., \& Saint-Aubin, J. (2005). What children are looking at during shared storybook 
reading: Evidence from eye movement monitoring. Psychological Science, 16, 913-920. doi:10.1111/j.1467-9280.2005.01636.x

Evans, M. A., \& Saint-Aubin, J. (2013). Vocabulary acquisition without adult explanations in repeated shared book reading: An eye movement study. Journal of Educational Psychology, 105, 596-608. doi:10.1037/a0032465

Farrant, B. M., \& Zubrick, S. R. (2013). Parentchild book reading across early childhood and child vocabulary in the early school years: Findings from the Longitudinal Study of Australian Children. First Language, 33, 280-293. doi:10.1177/0142723713487617

Flores, E. P., Pires, L. F., \& Souza, C. B. A. (2014). Dialogic reading of a novel for children: Effects on text comprehension. Paidéia (Ribeirão Preto), 24, 243-251. doi:10.1590/198243272458201412

Ganea, P. A., Allen, M. L., Butler, L., Carey, S., \& DeLoache, J. S. (2009). Toddlers' referential understanding of pictures. Journal of Experimental Child Psychology, 104, 283-295. doi:10.1016/j. jecp.2009.05.008

Greer, R. D., \& Du, L. (2015). Experience and the onset of the capability to learn names incidentally by exclusion. The Psychological Record, 65, 355-373. doi:10.1007/s40732-014-0111-2

Halberda, J. (2006). Is this a dax which I see before me? Use of the logical argument disjunctive syllogism supports word-learning in children and adults. Cognitive Psychology, 53, 310-344. doi:10.1016/j.cogpsych.2006.04.003

Heibeck, T. H., \& Markman, E. M. (1987). Word learning in children - An examination of fast mapping. Child Development, 58, 1021-1034. doi:10.2307/1130543

Horst, J. S. (2013). Context and repetition in word learning. Frontiers in Psychology, 4(149), 1-29. doi:10.3389/fpsyg.2013.00149

Horst, J., Parsons, K., \& Bryan, M. (2011). Get the story straight: Contextual repetition promotes word learning from storybooks. Frontiers in Developmental Psychology, 2(17), 1-11. doi:10.3389/fpsyg.2011.00017

Justice, L. M. (2002). Word exposure conditions and preschoolers' novel word learning during shared storybook reading. Reading Psychology, 23, $87-$ 106.
Justice, L. M., Skibbe, L. E., Canning, A., \& Lankford, C. (2005). Preschoolers, print, and storybooks: An observational study using eye-gaze analysis. Journal of Research in Reading, 28, 229-243. doi:10.1111/j.1467-9817.2005.00267.x

Kucirkova, N., Messer, D., \& Sheehy, K. (2014). Reading personalized books with preschool children enhances their word acquisition. First Language, 34, 227-243. doi:10.1177/0142723714534221

McIlvane, W. J., \& Stoddard, L. T. (1981). Acquisition of matching- to- sample performances in severe mental retardation: Learning by exclusion. Journal of Mental Deficiency Research, 25, 33-48.

Mintz, T. H., \& Gleitman, L. (2002). Adjectives really do modify nouns: The incremental and restricted nature of early adjective acquisition. Cognition, 84(3), 267-293.

Mol, S. E., Bus, A. G., de Jong, M. T., \& Smeets, D. J. (2008). Added value of dialogic parentchild book readings: A meta-analysis. Early Education and Development, 19, 7-26. doi:10.1080/10409280701838603

Oshiro, C. K. B., de Souza, D. G., \& Costa, A. R. A. (2006). Responder por exclusão a partir de uma linha de base de discriminações condicionais visuais. Revista Brasileira de Análise do Comportamento, 2, 251-276. doi:10.18542/rebac. v2i2.816

Robbins, C., \& Ehri, L. C. (1994). Reading storybooks to kindergartners helps them learn new vocabulary words. Journal of Educational Psychology, 86, 54-64. doi:10.1037/0022-0663.86.1.54

Rowe, M. L. (2000). Pointing and talk by lowincome mothers and their 14-month-old children. First Language, 20, 305-330. doi:10.1177/014272370002006005

Skinner, B. F. (1957). Verbal behavior. New York: Appleton-Century-Crofts.

Stemmer, N. (1996). Listener behavior and ostensive learning. Journal of the Experimental Analysis of Behavior, 65, 247-249. doi:10.1901/ jeab.1996.65-247

Thoermer, C., \& Sodian, B. (2001). Preverbal infants' understanding of referential gestures. First Language, 21(63), 245-264. doi:10.1177/014272370102106303

Tomasello, M., Carpenter, M., \& Liszkowski, U. (2007). A new look at infant pointing. Child 
Development, 78(3), 705-722. doi:10.1111/ j.1467-8624.2007.01025.x

Vichi, C., Nascimento, G. S., \& Souza, C. B. A. (2012). Aprendizagem ostensiva, comportamento de ouvinte e transferência de função por pareamento de estímulos. Revista Brasileira de Terapia Comportamental e Cognitiva, 14, 1630.

Wilkinson, K. M., de Souza, D. G., \& McIlvane, W. J. (2000). Origens da exclusão. Temas em Psicologia, 8, 195-203.

Wilkinson, K. M., Dube, W. V., \& McIlvane, W. J. (1998). Fast mapping and exclusion (emergent matching) in developmental language, behavior analysis, and animal cognition research. The Psychological Record, 48, 407-422.

Wilkinson, K. S., \& Houston-Price, C. (2013). Once upon a time, there was a pulchritudinous princess...: The role of word definitions and multiple story contexts in children's learning of difficult vocabulary. Applied Psycholinguistics, 34(3), 591-613. doi:10.1017/S0142716411000889
Yu, C., \& Ballard, D. H. (2007). A unified model of early word learning: Integrating statistical and social cues. Neurocomputing, 70, 2149-2165. doi:10.1016/j.neucom.2006.01.034

Yu, C., \& Smith, L. B. (2012). Embodied attention and word learning by toddlers. Cognition, 125, 244-262. doi:10.1016/j.cognition.2012.06.016

Zucker, T. A., Cabell, S. Q., Justice, L. M., Pentimonti, J. M., \& Kaderavek, J. N. (2013). The role of frequent, interactive prekindergarten shared reading in the longitudinal development of language and literacy skills. Developmental Psychology, 49, 1425-1439. doi:10.1037/a0030347

Recebido: 20/02/2015

$1^{a}$ revisão: $23 / 10 / 2015$

Aceite final: 08/12/2015 